\title{
Effect of temperature on the morphological and photovoltaic stability of bulk heterojunction polymer:fullerene solar cells
}

Sabine Bertho ${ }^{\mathrm{a}, *}$, Griet Janssen ${ }^{\mathrm{b}}$, Thomas J. Cleij ${ }^{\mathrm{a}}$, Bert Conings ${ }^{\mathrm{a}}$, Wouter Moons ${ }^{\mathrm{a}}$, Abay Gadisa $^{\mathrm{c}}$, Jan D'Haen ${ }^{\mathrm{a}}$, Etienne Goovaerts ${ }^{\mathrm{b}}$, Laurence Lutsen ${ }^{\mathrm{c}}$, Jean Manca ${ }^{\mathrm{a}, \mathrm{c}}$, Dirk Vanderzande $\mathrm{e}^{\mathrm{a}, \mathrm{c}}$

${ }^{a}$ Hasselt University, Institute for Materials Research, Wetenschapspark 1, Diepenbeek, B-3590, Belgium

${ }^{\mathrm{b}}$ University of Antwerp, Physics Department, Universiteitsplein 1, B-2610 Antwerp, Belgium

'IMECvzw, IMOMEC, Diepenbeek, B-3590, Belgium

e-mail: sabine.bertho@uhasselt.be

\begin{abstract}
In high performance polymer:fullerene bulk heterojunction solar cells the nanoscale morphology of interpenetrating acceptor:donor materials is optimised through appropriate preparation conditions such as annealing and choice of solvent, but this initial state-of-the-art morphology will not remain stable during long term operation. We report the effects of prolonged storage at elevated temperatures on both the morphology and the photovoltaic performance for the model systems MDMOPPV:PCBM and P3HT:PCBM as compared to 'High $\mathrm{T}_{\mathrm{g}}$ PPV':PCBM based solar cells, where the 'High $\mathrm{T}_{\mathrm{g}} \mathrm{PPV}$ ' is characterised by its high glass transition temperature $\left(138^{\circ} \mathrm{C}\right)$. In-situ monitoring of the photo-current-voltage characteristics at elevated temperatures, in combination with a systematic Transmission Electron Microscopy (TEM) study and complementary optical spectroscopy, reveals distinct degradation
\end{abstract}


kinetics and morphological changes that indicate the occurrence of different underlying physico-chemical mechanisms.

Keywords: Organic photovoltaics, thermal stability, glass transition temperature, morphology

\section{Introduction}

In the historical development towards state-of-the-art polymer:fullerene bulk heterojunction solar cells the nanoscale morphology of the photoactive film always played a crucial role [1-4]. In bulk heterojunction solar cells the morphology of the donor-acceptor interpenetrating networks is fine tuned in order to optimize the combination of both exciton dissociation and charge transport. Moreover, the short exciton diffusion length in these material systems $(5-10 \mathrm{~nm})$ demands proximity of the donor and acceptor regions on nanoscale. The nanoscale morphology of the interpenetrating acceptor:donor materials is optimised through appropriate preparation conditions such as annealing conditions and choice of solvents. For the model system MDMO-PPV:PCBM, improvement of the film morphology has been obtained by switching to the use of chlorobenzene as a solvent, resulting in 2.5 to $2.9 \%$ efficient organic solar cells $[3,4]$. Nowadays efficiencies of $5 \%$ are achieved through the use of high mobility donor polymers (e.g. P3HT) and through a continued nanoscale control of the morphology of the donor-acceptor interpenetrating networks - which in some cases has been realized by the introduction of an additional annealing step $[5,6]$. However, in this paper it will be demonstrated that this initial optimized morphology will not remain stable during long term operation or during storage at elevated temperatures and 
therefore becomes one of the multiple stability issues encountered in organic solar cells. Organic solar cells degrade because of their low resistance towards oxygen, light, high temperatures etc. [7-16]. We will focus here on the instability of organic solar cells that results from morphological changes in the active layer due to a thermal treatment [1719]. In particular, the relation between the morphological instability and the glass transition temperature of the donor materials is studied in more detail. We investigated the effect of temperature on the morphology as well as on the photovoltaic performance of three polymer:fullerene material systems: the model systems MDMO-PPV:PCBM and P3HT:PCBM as compared to 'High $\mathrm{T}_{\mathrm{g}}$ PPV':PCBM, based on a conjugated polymer with a high glass transition temperature. The photovoltaic output (i.e. the short circuit current, open circuit voltage, fill factor and efficiency) was studied in-situ at various annealing temperatures. Complementary with this in-situ electrical monitoring of the degradation kinetics, the evolution of the active layer morphology was studied with Transmission Electron Microscopy (TEM) and optical and photoluminescence absorption spectroscopy results are discussed.

\section{Experimental}

Bulk heterojunction solar cells with three different conjugated polymers (MDMO-PPV(Poly[2-methoxy-5-(3',7'-dimethyloctyloxy)-1,4-phenylene vinylene]) with $\mathrm{T}_{\mathrm{g}} \approx 50^{\circ} \mathrm{C}, \mathrm{P} 3 \mathrm{HT}\left(\right.$ poly(3-hexylthiophene)) with $\mathrm{T}_{\mathrm{g}} \approx 6^{\circ} \mathrm{C}[20-23]$ and 'High $\mathrm{T}_{\mathrm{g}}$ PPV' with $\mathrm{T}_{\mathrm{g}} \approx 138^{\circ} \mathrm{C}$, all supplied by Merck) as electron donor materials and PCBM ([6-6]-phenyl $\mathrm{C}_{61}$ butyric acid methyl ester (Nano-C)) as acceptor material were made according to the following preparation guidelines. The devices had a ITO/PEDOTPSS/polymer:PCBM/Al structure. Each device had an active area of $25.0 \mathrm{~mm}^{2}$. Indium 
tin oxide (ITO, 100nm) coated glass plates were successively cleaned in a soap solution, demineralised water and acetone, each for 10 minutes in an ultrasonic bath. This was followed by cleaning in boiling isopropanol for 10 minutes. A 60nm thick Poly(3,4ethylenedioxythiophene-polystyrenesulfonate (PEDOT-PSS (Bayer)) layer was spincoated on the clean glass/ITO substrates. The substrates were dried for 20 minutes on a hotplate at $120^{\circ} \mathrm{C}$. The active layer, with thickness of $120 \mathrm{~nm}$, consisting of a blend of polymer and PCBM in chlorobenzene was spincoated on top of the PEDOT-PSS layer. The polymer:PCBM ratio for MDMO-PPV, 'High $\mathrm{T}_{\mathrm{g}} \mathrm{PPV}$ ' and P3HT were respectively 1:4, 1:4 and 1:1 (these ratios were chosen because they resulted in the best solar cell performance). The concentrations of the solutions were respectively $0.5 \mathrm{wt} \%$, $0.3 \mathrm{wt} \%$ and $1.0 \mathrm{wt} \%$ (weight percentage of polymer in chlorobenzene solvent) for MDMO-PPV, 'High $\mathrm{T}_{\mathrm{g}}$ PPV' and P3HT. To obtain complete dissolution of MDMOPPV:PCBM and P3HT:PCBM, these solutions were stirred overnight at $50^{\circ} \mathrm{C}$; the 'High $\mathrm{T}_{\mathrm{g}}$ PPV':PCBM solution was stirred for 3 days at $50^{\circ} \mathrm{C}$. The solar cells were completed by evaporating $80 \mathrm{~nm}$ of $\mathrm{Al}$ on top of the active layer.

The IV-characteristics were measured with an Oriel solar simulator equipped with a Xenon Short Arc lamp with a power of $150 \mathrm{~W}$. The influence of thermal annealing on the photovoltaic performance was measured in a set-up that measures IVcharacterisations at regular time intervals (illumination with a White 5500K LED (Lamina)) while the samples were kept under continuous annealing. In between the measurements, the samples were kept in the dark.

Values for the glass transition temperature $\left(\mathrm{T}_{\mathrm{g}}\right)$ of the 'High $\mathrm{T}_{\mathrm{g}}$ PPV' were determined by UV-Vis spectroscopy. To this end, an Ocean Optics USB2000 spectrometer with fiber optics arrangement was used. Samples were prepared by 
spincoating the polymer from a $1.0 \mathrm{wt} \%$ solution in chlorobenzene onto a quartz substrate. Subsequently the substrate was placed in a Linkam TMS94/THMS600 controlled heating/freezing stage, which was positioned in the optical path of the UVVis spectrophotometer. The sample was then heated from room temperature to $200^{\circ} \mathrm{C}$ (heating rate: $5^{\circ} \mathrm{C} / \mathrm{min}$ ) and subsequently cooled (cooling rate: $5^{\circ} \mathrm{C} / \mathrm{min}$ ) to room temperature. Each measurement point was obtained by averaging 500 individual UVVis absorption spectra. The second heating run was used for the determination of the $\mathrm{T}_{\mathrm{g}}$.

The active layer morphology was studied with a Transmission Electron Microscope (Philips CM12-STEM). A Varian Cary absorption spectrometer and a Varian Cary Eclipse fluorometer (excitation wavelength of $485 \mathrm{~nm}$ ) were used for the optical absorption and photoluminescence (PL) measurements respectively.

\section{Results and discussion}

\section{1 'High $T_{g} P P V$ '}

As described earlier, 'High $\mathrm{T}_{\mathrm{g}} \mathrm{PPV}$ ' is characterised by its rather high glass transition temperature as compared to MDMO-PPV and P3HT. This means that its blend with PCBM allows a wide window for investigation of thermal degradation under elevated temperature conditions. However, while P3HT and MDMO-PPV are well studied materials, 'High $\mathrm{T}_{\mathrm{g}} \mathrm{PPV}$ ', is not well known and therefore requires an appropriate introduction. Figure 1 shows the chemical structure of the conjugated polymer that we call 'High $\mathrm{T}_{\mathrm{g}} \mathrm{PPV}$ ' for simplicity. The material is a copolymer designed by Merck. The synthetic route is described elsewhere by Becker et al. [24].

The glass transition temperatures of MDMO-PPV and $\mathrm{P} 3 \mathrm{HT}$ (respectively $50^{\circ} \mathrm{C}$ and $12^{\circ} \mathrm{C}$ ) were determined through Differential Scanning Calorimetry (DSC) 
measurements. The glass transition temperature of 'High $\mathrm{T}_{\mathrm{g}}$ PPV' was indicated by Merck to be about $150^{\circ} \mathrm{C}$ but no $\mathrm{T}_{\mathrm{g}}$ could be observed with conventional DSC measurements. Therefore, the $T_{g}$ value of 'High $T_{g}$ PPV' was verified by the following method. Many conjugated polymers exhibit typical thermochromic properties. In PPVtype polymers, this thermochromism allows for a direct determination of previously inaccessible $T_{g}$ values. This is a result of the fact that these thermochromic effects are directly correlated with temperature dependent deviations from planarity of the conjugated system, which occur above the glass transition temperature $T_{g}$. Below the $T_{g}$ the backbone conformation no longer changes and as a result no thermochromism but only ground-state aggregation phenomena are observed. As a result, for PPV-type polymers an accurate value for the $T_{g}$ can be determined from temperature dependent UV-Vis absorption spectra. A $T_{g}$ measurement of the 'High $T_{g} P P V$ ' is displayed in Figure 2. By plotting the wavelength $\lambda$ at half maximum of the $\pi-\pi^{*}$ transition as a function of temperature, two linear fits with different slopes are obtained. For these fits the measurements close to the $\mathrm{T}_{\mathrm{g}}$, i.e. at $130^{\circ} \mathrm{C}$ and $140^{\circ} \mathrm{C}$ were omitted. The intersection of the obtained fits gives an accurate estimate of the $\mathrm{T}_{\mathrm{g}}$ of the polymer. For 'High $\mathrm{T}_{\mathrm{g}}$ PPV' it was determined to be $138^{\circ} \mathrm{C}$. Furthermore, from Figure 2 it is evident that the $T_{g}$ is well defined, since the entire transition occurs within the limited temperature range of $120^{\circ} \mathrm{C}$ to $150^{\circ} \mathrm{C}$.

In order to demonstrate that 'High $\mathrm{T}_{\mathrm{g}} \mathrm{PPV}$ ' is suitable as donor material in bulk heterojunction solar cells, Figure 3 shows a current-voltage (IV) characteristic of a solar cell prepared with 'High $\mathrm{T}_{\mathrm{g}}$ PPV'. Such solar cells gave an overall efficiency around $1.5 \%$. Remarkable though is the high open circuit voltage of $0.83 \mathrm{~V}$. 


\subsection{In-situ monitoring of photovoltaic degradation kinetics}

In the following, several experiments are performed at elevated temperatures to speed up the degradation processes inside the solar cells presented above. Figure 4 shows the relative decay of the photovoltaic parameters of a solar cell with an MDMOPPV:PCBM 1:4 blend as active layer for an annealing temperature of $110^{\circ} \mathrm{C}$. As can be inferred from the figure, the open circuit voltage $\left(\mathrm{V}_{\text {oc }}\right)$ is barely sensitive to the thermal treatment performed over a long period of time. This is consistent with the fact that $\mathrm{V}_{\mathrm{oc}}$ mainly depends on material properties, namely the ionization potential of the donor polymer and electron affinity of the acceptor fullerene molecule. Only a relatively small decrease in $\mathrm{V}_{\mathrm{oc}}$ (less than 10\%) is observed. A larger decrease is observed in the short circuit current $\left(\mathrm{I}_{\mathrm{sc}}\right)$ and the fill factor $(\mathrm{FF})$. The efficiency of the solar cell, proportional to $\mathrm{I}_{\mathrm{sc}}, \mathrm{V}_{\mathrm{oc}}$ and $\mathrm{FF}$, shows the largest decrease.

Figure 5 shows the decay of the short circuit current for solar cells based on the three materials (MDMO-PPV, 'High $\mathrm{T}_{\mathrm{g}}$ PPV' and P3HT) for several annealing temperatures. At room temperature, the short circuit current of the PPV-derivatives stays rather constant for several hours. Once the samples are annealed, a clear difference can be observed in the decay characteristics of the three materials. Solar cells based on MDMO-PPV show a monotonous decay. For P3HT based solar cells, $\mathrm{I}_{\mathrm{sc}}$ increases for relatively short annealing times. After a certain time, which depends on the annealing temperature, $\mathrm{I}_{\mathrm{sc}}$ starts to decrease (as can be observed for $\mathrm{T}=110^{\circ} \mathrm{C}$ and $150^{\circ} \mathrm{C}$ ). On the contrary, solar cells based on 'High $\mathrm{T}_{\mathrm{g}} \mathrm{PPV}$ ' remain rather stable, with no large impact of the annealing temperature up to $150^{\circ} \mathrm{C}$.

\subsection{Morphology vs thermal annealing}


Previous studies have already shown a strong correlation between the morphology of the active layer of solar cells and their performance [3,25]. Here we will demonstrate that the behavior of the short circuit current of the solar cells depicted in Figure 5 can also be linked to morphology changes taking place in the active layer. Figure 6 shows Bright Field TEM-images of the evolution of the active layers of MDMO-PPV:PCBM (1:4) and 'High $\mathrm{T}_{\mathrm{g}}$ PPV':PCBM (1:4) during annealing at $110^{\circ} \mathrm{C}$. In earlier work [26], it was already presented that the active layer morphology of 'High $\mathrm{T}_{\mathrm{g}}$ PPV':PCBM is much more stable than MDMO-PVV:PCBM. The high glass transition temperature of 'High $\mathrm{T}_{\mathrm{g}} \mathrm{PPV}$ ' results in a firm polymer:PCBM matrix where the demixing of the two components is hampered. This difference in morphological stability coincides with the observed decay of the short circuit current in Figure 5. The slower decay of $\mathrm{I}_{\mathrm{sc}}$ for the 'High $\mathrm{T}_{\mathrm{g}}$ PPV':PCBM based solar cells can be attributed to a more stable active layer morphology.

The evolution of $\mathrm{I}_{\mathrm{sc}}$ for P3HT:PCBM 1:1 solar cells shown in Figure 5 can also be linked to the active layer morphology. Bright Field TEM images show that after 4 hours of annealing at $110^{\circ} \mathrm{C}, \mathrm{PCBM}$ starts to cluster (Figure 7a). For this material however more information can be gathered from the SAED patterns of the P3HT:PCBM matrix in between the clusters. Figure $7 \mathrm{~b}$ shows the residual intensities of these patterns for annealing at $110^{\circ} \mathrm{C}$ for several hours. The original diffraction patterns suffered from a large background that resembled inelastic scattering. To improve the signal-to-noise ratio, integration across the complete diffraction ring was done, from which a calculated background due to inelastic scattering was subtracted (under the assumption that the blend in between the clusters is quasi-amorphous[27]). The residual intensities of the SAED pattern of the non-annealed active layer shows distinct peaks at 
d-values of $2 \AA, 3.1 \AA$ and $4.6 \AA$ corresponding to nanocrystalline PCBM [28]. In addition, for annealing times between $0.5 \mathrm{~h}$ and $8 \mathrm{~h}$, some evolution in the intensity can be seen at $3.8 \AA$. The peak appearing here can be attributed to the superposition of the (002) and (020) reflections from the crystal planes of semi-crystalline P3HT [23]. After 16 hours of annealing, the P3HT peak is very pronounced in the SAED pattern. At the same time, the peaks corresponding to nanocrystalline PCBM are reducing. At this point, P3HT has formed fibre-like crystalline structures that can be seen clearly in a Bright Field TEM image (Figure 7c). On the other hand, PCBM is vanishing from the P3HT:PCBM matrix and gathering in the PCBM-clusters.

It is clear now that in P3HT:PCBM active layers, two processes take place [29]. One of them, namely the local crystallization of P3HT into fibre-like structures, leads to better charge transport, resulting in a higher $\mathrm{I}_{\mathrm{sc}}$. The other process, as in blends with MDMO-PPV, is again the clustering of PCBM, which at later times results in a decrease of $\mathrm{I}_{\mathrm{sc}}$ mainly due to a lower interfacial area between P3HT and PCBM.

\subsection{Thermal stability reflected in absorption and emission}

The better thermal stability of 'High $\mathrm{T}_{\mathrm{g}}$ PPV' as compared to MDMO-PPV and P3HT is also confirmed by optical spectroscopy. Figure 8 shows the absorption spectra of MDMO-PPV:PCBM (1:4), 'High T $\mathrm{T}_{\mathrm{g}}$ PPV':PCBM (1:4) and P3HT:PCBM (1:1) films. An annealing treatment of 16 hours at $110^{\circ} \mathrm{C}$ results in a quite remarkable change of the absorption spectrum of the MDMO-PPV:PCBM blend. The disappearance of the PCBM-absorption in the spectrum of this blend reflects the growth of PCBM crystallites as observed by TEM in the previous paragraph. 
Indeed, since the optical spectrometer works in a transmission mode, the dense PCBM crystals give rise to tremendous light scattering. As a result, the total transparent film area is reduced, explaining the appearance of an overall background in the spectrum. Only the polymer regions - essentially PCBM free - contribute to the spectrum. The absorption of the 'High $\mathrm{T}_{\mathrm{g}}$ PPV':PCBM film is stable during long thermal treatments, which directly reflects the higher thermal stability of its morphology.

The absorption spectra for the P3HT:PCBM blend reflect the dual crystallization behavior. For the as-produced P3HT:PCBM blend the PCBM-absorption is lower than for the PPV-derivatives because a lower amount of PCBM is used (a polymer:PCBM ratio of 1:1 instead of 1:4). However, also for this blend, the PCBM-absorption is reduced upon annealing, indicating the clustering of PCBM. For this blend, also a redshift for P3HT is observed, which indicates the ordering of P3HT into the fiber-like crystalline structures that were visible in de Bright Field TEM images[30].

An essential step in the PV effect, the electron transfer from polymer to fullerene, can be monitored by the degree of PL quenching, which is close to complete in the unannealed blend films (see Fig. 9, as produced films). In the pure MDMO-PPV film, a drastic change in shape and peak intensity is observed in the first few minutes of the treatment at $110^{\circ} \mathrm{C}$ after which the spectrum remains unaltered for hours. This initial change is not related to degradation of the polymer, but should rather be ascribed to local rearrangements of the polymer chains. (While not discernable in the figure, the same fast change in shape is observed upon heating in the blend of MDMO-PPV with PCBM). No such initial effect is found in the 'High $\mathrm{T}_{\mathrm{g}} \mathrm{PPV}$ ' film, and only a minor change is observed in both shape and intensity even after $16 \mathrm{~h}$ of annealing at $110^{\circ} \mathrm{C}$. 
A thermal treatment of $16 \mathrm{~h}$ increases the emission intensity of each of the blends, pointing to decreasing charge transfer efficiency. This is much more pronounced in the blend with MDMO-PPV compared to 'High $\mathrm{T}_{\mathrm{g}}$ PPV', which correlates well with the higher stability of the morphology in the latter. The decrease in charge transfer efficiency is attributed to the clustering of the PCBM, reducing the interfacial area between the two components of the blend. The TEM investigation has clearly demonstrated the importance of segregation and clustering in MDMO-PPV:PCBM blends, which is hardly observed for 'High $\mathrm{T}_{\mathrm{g}}$ PPV':PCBM blends.

\section{Conclusion}

For the three materials (MDMO-PPV, P3HT and 'High $\mathrm{T}_{\mathrm{g}}$ PPV') a clear correlation between the morphological evolution of the active layer of solar cells and the degradation of their characteristics is demonstrated. The active layers based on MDMO-PPV show a rapid formation of PCBM-clusters upon annealing. The smaller interfacial area between electron acceptor and electron donor results in a lower photocurrent output. P3HT shows a dual crystallization behavior: on the one hand, P3HT crystallizes, which leads to improved charge conduction and a higher photocurrent output; on the other hand, PCBM groups into clusters, again reducing the interfacial area between electron acceptor and donor regions, which results in a decrease in photocurrent. Comparing the three materials, morphology changes are strongly suppressed in the 'High $\mathrm{T}_{\mathrm{g}} \mathrm{PPV}$ ' active layers which leads to the demonstrated high thermal stability of the device characteristics. Due to the higher glass transition temperature of 'High $\mathrm{T}_{\mathrm{g}}$ PPV', its matrix is firmer. This strongly restricts the possible 
migration and segregation of the PCBM molecules leading to a more stable active layer and consequently to a more stable photovoltaic behavior.

The thermal stability of the MDMO-PPV and 'High $\mathrm{T}_{\mathrm{g}}$ PPV' polymer films is also reflected in the stability of the UV-VIS absorption spectra. The charge transfer, monitored by the degree of PL quenching, is much less affected by the thermal treatment in the blends with 'High $\mathrm{T}_{\mathrm{g}}$ PPV' than with MDMO-PPV, which is directly related to their very different morphological evolution.

\section{Acknowledgements}

The research was carried out in the framework of the IWT-project 030220 "Nanosolar", the FWO-project G.0252.04 and the interregional project OLED+. The work, as part of the project "SOHYDs" within the European Science Foundation EUROCORES Programme was also supported from funds by the FWO (G.0685.06) and the EC Sixth Framework Programme, under contract N. ERAS-CT-2003-980409. Sabine Bertho is research assistant of the Fund for Scientific Research, Flanders (Belgium) (F.W.O.). We thank Dr. H. Becker of Merck OLED Materials GmbH for the supply of the 'High $\mathrm{T}_{\mathrm{g}}$ PPV'.

\section{References}

[1] G. Yu, J. Gao, J.C. Hummelen, F. Wudl, A.J. Heeger, Science 270 (1995) 1789.

[2] L.S. Roman, M.R. Andersson, T. Yohanms, Adv. Mater. 9 (1997) 1164.

[3] S.E. Shaheen, C.J. Brabec, N.S. Sariciftci, F. Padinger, T. Fromherz, J.C.

Hummelen, Appl. Phys. Lett. 78 (2001) 841. 
[4] T. Munters, T. Martens, L. Goris, V. Vrindts, J. Manca, L. Lutsen, W. De Ceuninck, D. Vanderzande, L. De Schepper, J. Gelan, N.S. Sariciftci, C.J. Brabec, Thin Solid Films 403-404 (2002) 247.

[5] W. Ma, C. Yang, X. Gong, K. Lee, A.J. Heeger, Adv. Funct. Mater. 15 (2005) 1617. [6] F. Padinger, T. Fromherz, P. Denk, C.J. Brabec, J. Zettner, T. Hierl, N.S. Sariciftci, Synth. Met. 121 (2001) 1605.

[7] H. Neugebauer, C.J. Brabec, J.C. Hummelen, R.A.J. Janssen, N.S. Sariciftci, Synth. Met. 102 (1999) 1002.

[8] J.M. Kroon, M.M. Wienk, W.J.H. Verhees, J.C. Hummelen, Thin Solid Films 403404 (2002) 223.

[9] F.C. Krebs, J.E. Carlé, N. Cruys-Bagger, M. Andersen, M.R. Lilliedal, M.A. Hammond, S. Hvidt, Sol. Energy Mater. Sol. Cells 86 (2005) 499.

[10] S. Schuller, P. Schilinsky, J. Hauch, C.J. Brabec, Appl. Phys. A. 79 (2004) 37.

[11] H. Neugebauer, C. Brabec, J.C. Hummelen, N.S. Sariciftci, Sol. Energy Mater. Sol. Cells 61 (2000) 35 .

[12] N. Camaioni, G. Ridolfi, G. Casalbore-Miceli, G. Possamai, L. Garlaschelli, M. Maggini, Sol. Energy Mater. Sol. Cells 76 (2003) 107.

[13] H. Hoppe, N.S. Sariciftci, J. Mater.Res. 19 (2004) 1924.

[14] Z. Zhu, S. Hadjikyriacou, D. Waller, R. Gaudiana, J. Macromol. Sci., Part A: Pure Appl. Chem. 41 (2004) 1467.

[15] F.C. Krebs, H. Spanggaard, Chem. Mater. 17 (2005) 5235.

[16] F.C. Krebs, K. Norrman, Prog. Photovolt: Res. Appl. 15 (2007) 697

[17] X. Yang, J.K.J. van Duren, M.R. Rispens, J.C. Hummelen, R.A.J. Janssen, M.A.J. Michels, J. Loos, Adv. Mater. 16 (2004) 802. 
[18] X. Yang, J.K.J. van Duren, R.A.J. Janssen, M.A.J. Michels, J. Loos, Macromolecules 37 (2004) 2151.

[19] X. Yang, J. Loos, S.C. Veenstra, W.J.H. Verhees, M. Wienk, J.M. Kroon, M.A.J. Michels, R.A.J. Janssen, Nano Lett. 5 (2005) 579

[20] A. Swinnen, J. Zhao, G. Van Assche, D. Vanderzande, M. D'Olieslaeger, J. V. Manca, and B. Van Mele, Proc. SPIE 6656 (2007) 665619 (2007)

[21] Y. Zhao, G. Yuan, P. Roche, M. Leclerc, Polymer 36 (1995) 2211

[22] X. Hu, L. Xu, Polymer 41 (2000) 9147

[23] S. Hugger, R. Thomann, T. Heinzel, T. Thurn-Albrecht, Colloid. Polym. Sci. 282 (2004) 932

[24] H. Becker, H. Spreitzer, W. Kreuder, E. Kluge, H. Schenk, I. Parker, Y. Cao, Adv. Mater. 42 (2000) 42.

[25] T. Martens, J. D’Haen, T. Munters, Z. Beelen, L. Goris, J. Manca, M.

D’Olieslaeger, D. Vanderzande, L. De Schepper, R. Andriessen, Synth. Met. 138 (2003) 243.

[26] S. Bertho, I. Haeldermans, A. Swinnen, W. Moons, T. Martens, L. Lutsen, D. Vanderzande, J. Manca, A. Senes, A. Bonfiglio, Sol. Energy Mater. Sol. Cells 91 (2007) 385 .

[27] L. Reimer, Transmission Electron Microscopy, Springer-Verlag, 1989.

[28] M.T. Rispens, A. Meetsma, R. Rittberger, C.J. Brabec, N.S. Sariciftci, J.C. Hummelen, Chem. Commun. 17 (2003) 2116.

[29] A. Swinnen, I. Haeldermans, P. Vanlaeke, J. D'Haen, J. Poortmans, M. D'Olieslaeger, J. Manca, Eur. Phys. J. Appl. Phys.36 (3) (2006) 251-256. 
[30] P. Vanlaeke, A. Swinnen, I. Haeldermans, G. Vanhoyland, T. Aernouts, D.

Cheyns, C. Deibel, J. D’Haen, P. Heremans, J. Poortmans, J.V. Manca, Sol. Energy Mater. Sol. Cells 90 (2006) 2150. 
<smiles>CC=Cc1ccc(C)cc1-c1ccc(O)c(O)c1</smiles>

Figure 1. 'High $\mathrm{T}_{\mathrm{g}} \mathrm{PPV}$ ': a copolymer designed by Merck with a high glass transition temperature [24].

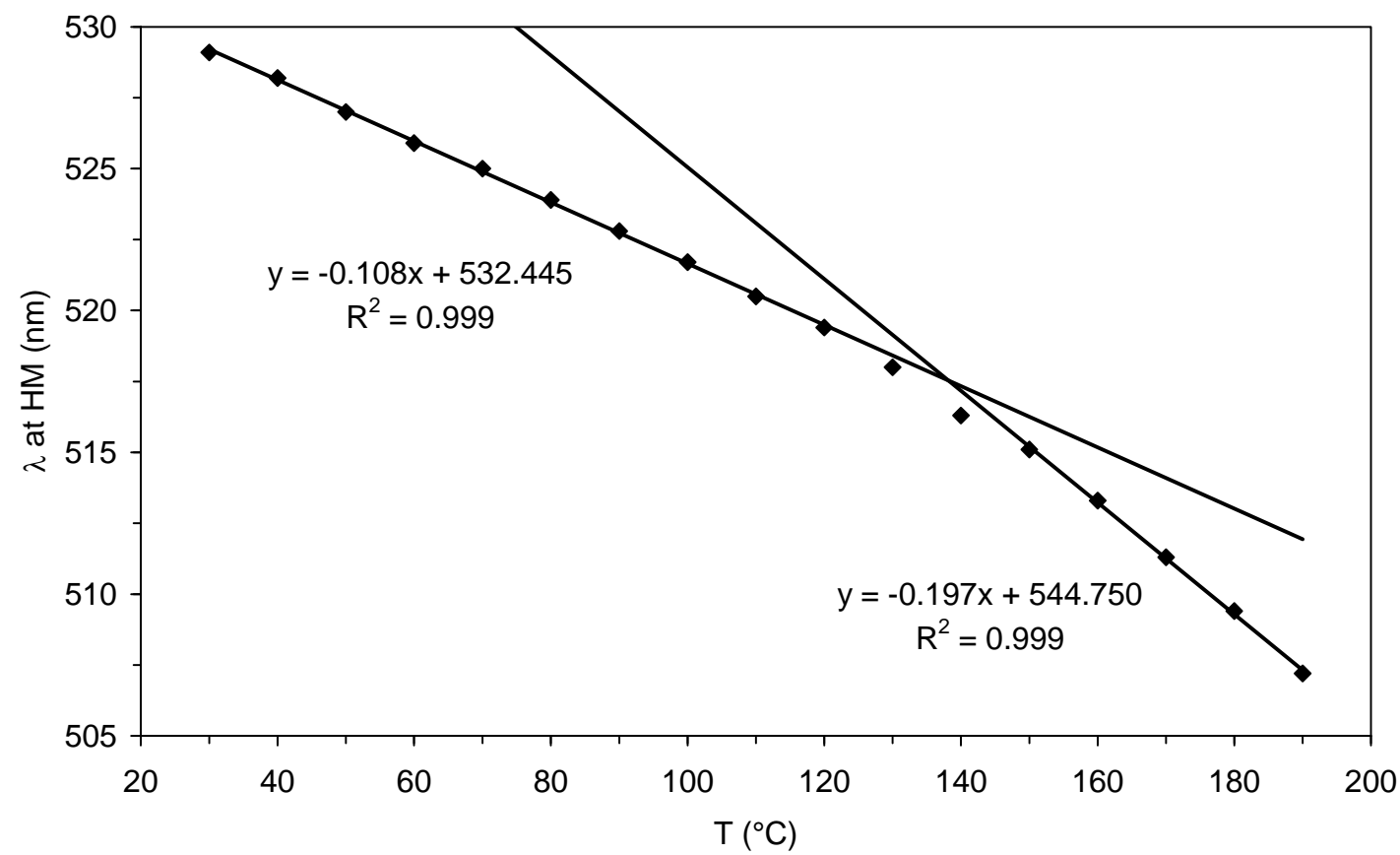

Figure 2. Graph of the wavelength $\lambda$ at half maximum of the $\pi-\pi^{*}$ transition as a function of temperature, two linear fits with different slopes are obtained. The intersection of the obtained fits gives a $\mathrm{T}_{\mathrm{g}}$ for 'High $\mathrm{T}_{\mathrm{g}} \mathrm{PPV}$ ' of $138^{\circ} \mathrm{C}$. 


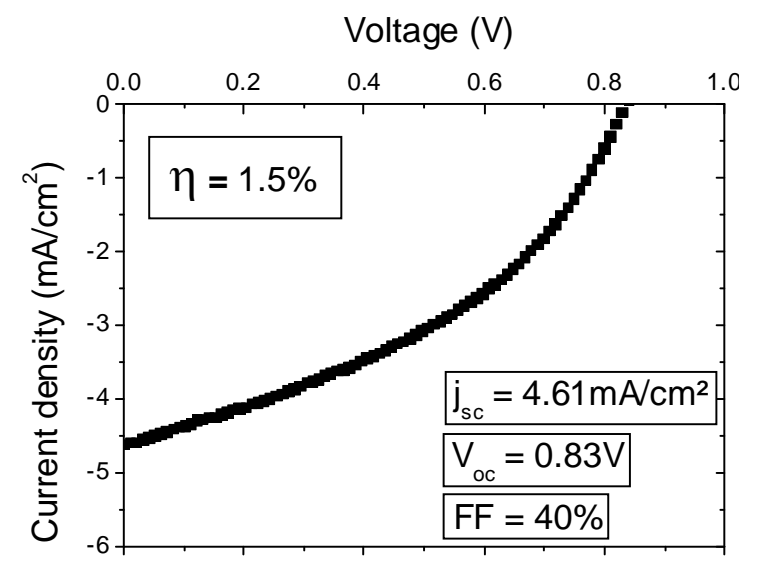

Figure 3. The current-voltage characteristics obtained from a 'High $\mathrm{T}_{\mathrm{g}}$ PPV':PCBM solar cell under AM 1.5 illumination.

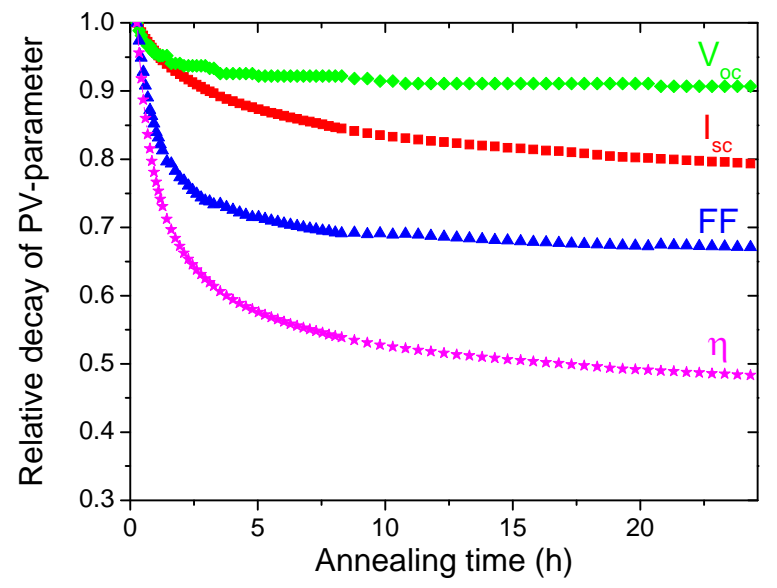

Figure 4. Relative decay of the short circuit current $\left(\mathrm{I}_{\mathrm{sc}}\right)$, open circuit voltage $\left(\mathrm{V}_{\mathrm{oc}}\right)$, fill factor (FF) and efficiency ( $\eta$ ) of an MDMO-PPV:PCBM 1:4 solar cell at $110^{\circ} \mathrm{C}$. 

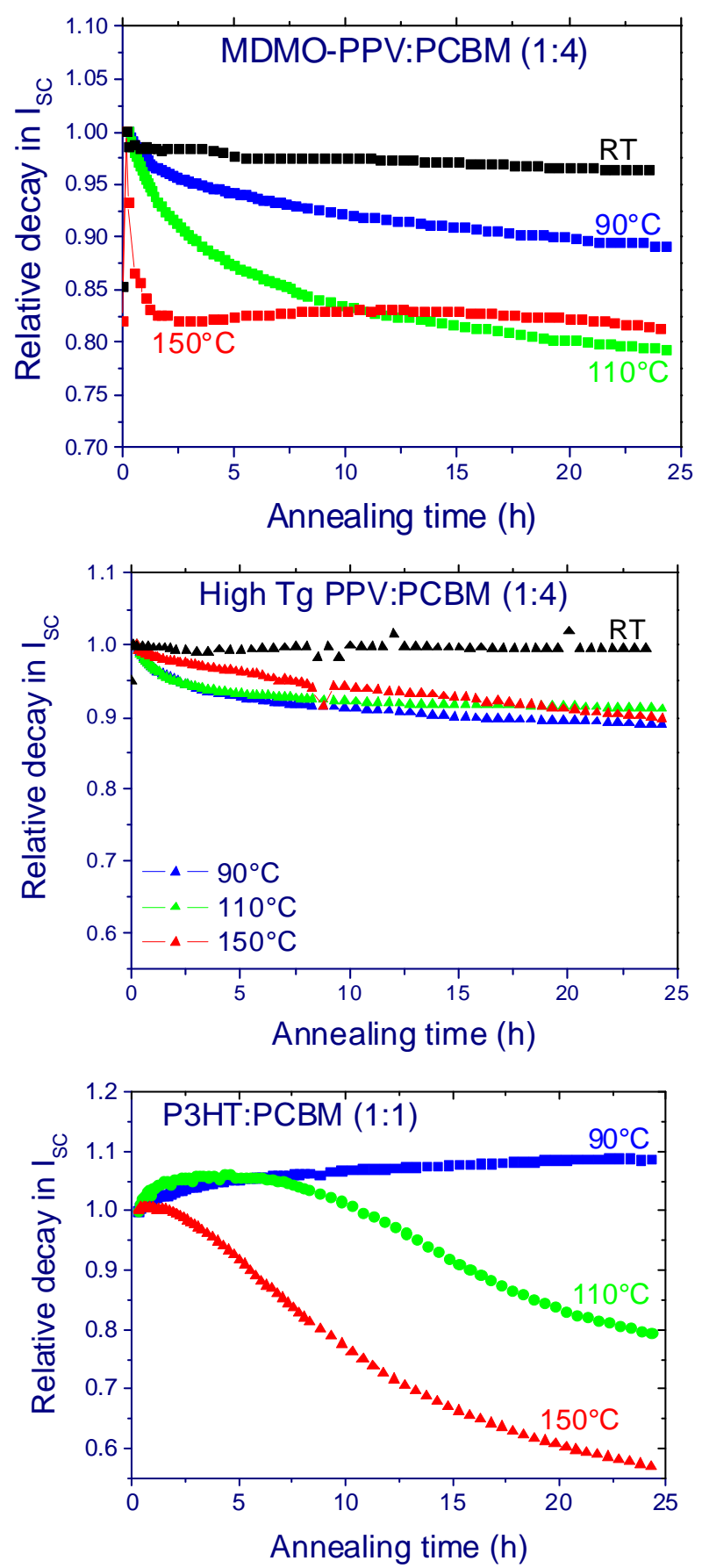

Figure 5. Relative decay of the short circuit current at several annealing temperatures for solar cells based on MDMO-PPV:PCBM (1:4), 'High $\mathrm{T}_{\mathrm{g}}$ PPV':PCBM (1:4) and P3HT:PCBM (1:1). 


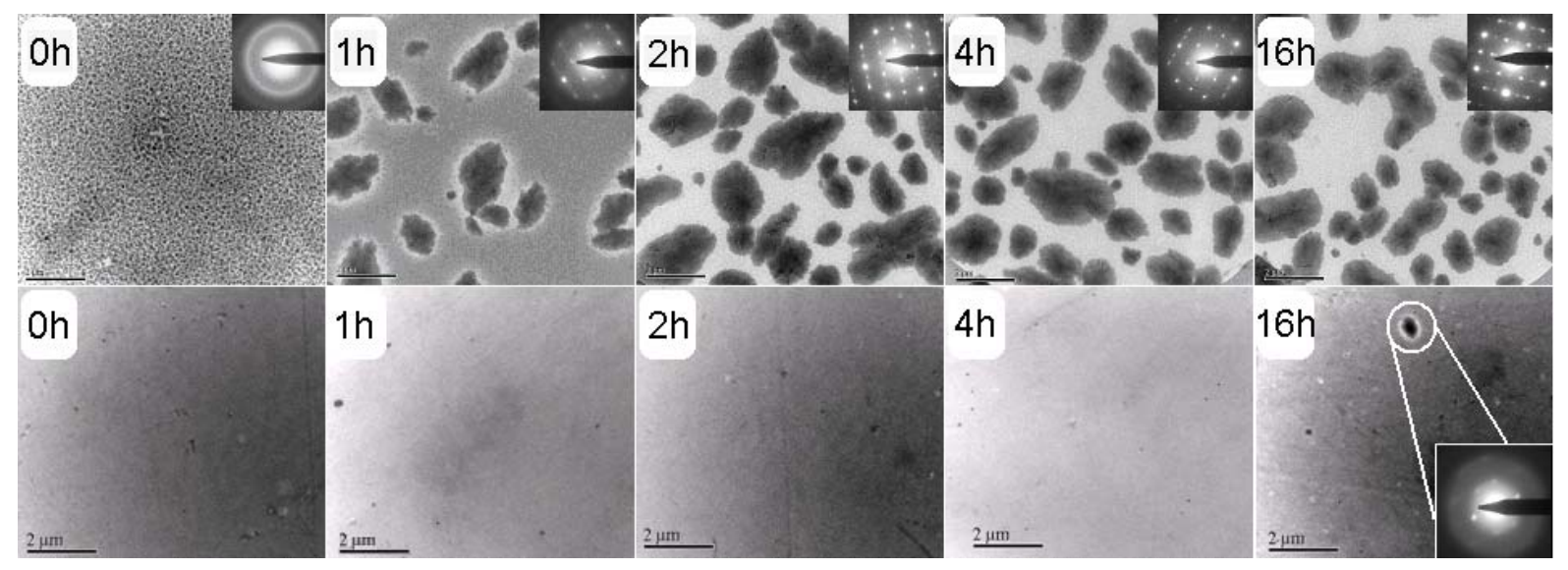

Figure 6. Morphology changes in the active layer of MDMO-PPV:PCBM 1:4 (top) and 'High $\mathrm{T}_{\mathrm{g}}$ PPV':PCBM 1:4 (bottom) as a result of annealing at $110^{\circ} \mathrm{C}$. The solar cells were annealed at $110^{\circ} \mathrm{C}$ for $0 \mathrm{~h}, 1 \mathrm{~h}, 2 \mathrm{~h}, 4 \mathrm{~h}$ and $16 \mathrm{~h}$ yielding formation of large PCBMclusters for the MDMO-PPV based active layers while maintaining a more stable morphology for the 'High $\mathrm{T}_{\mathrm{g}}$ PPV' based active layers (scale bar: $2 \mu \mathrm{m}$ ).
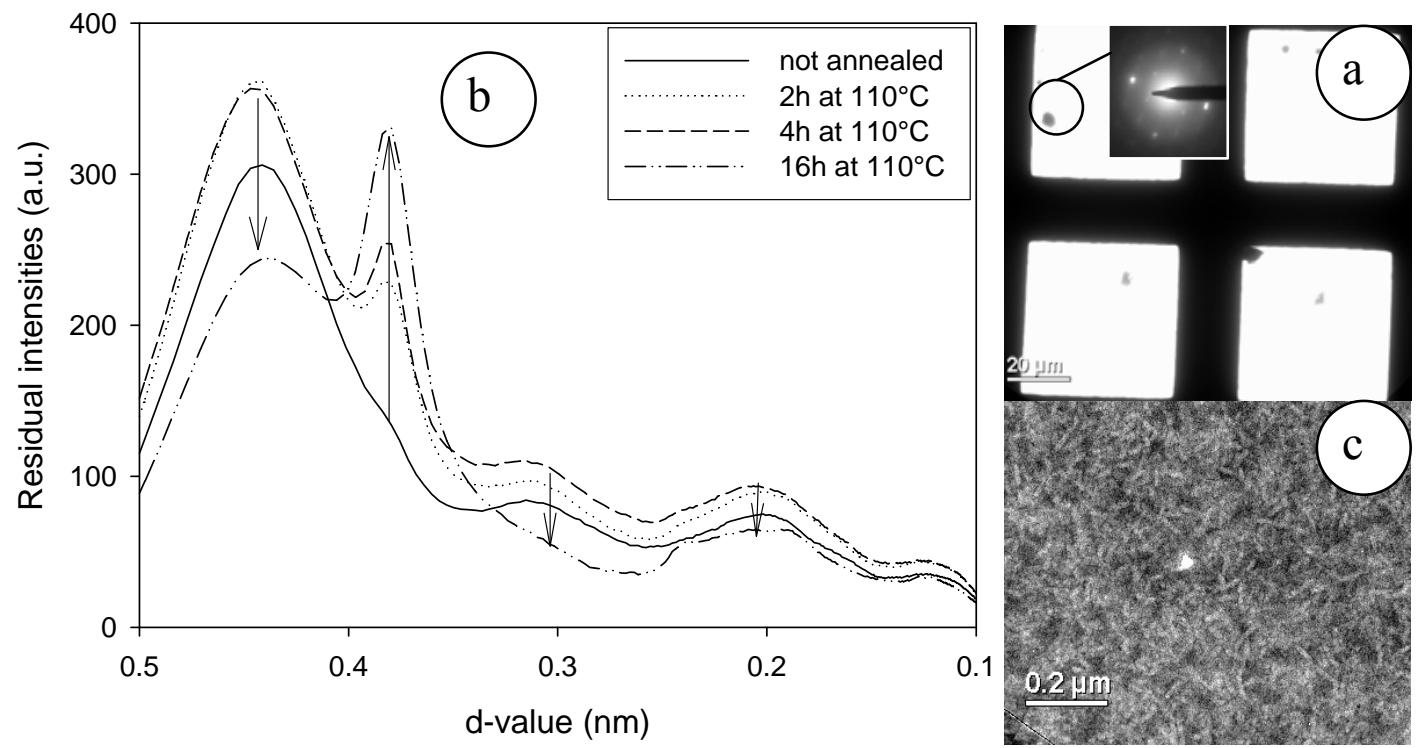

Figure 7. Evolution of a P3HT:PCBM (1:1) active layer during an annealing treatment at $110^{\circ} \mathrm{C}$, (a) after 4 hours some PCBM-clusters appear, (b) residual intensities of the SAED-patterns of the bulk, (c) P3HT-fibres are clearly visible after $16 \mathrm{~h}$. 

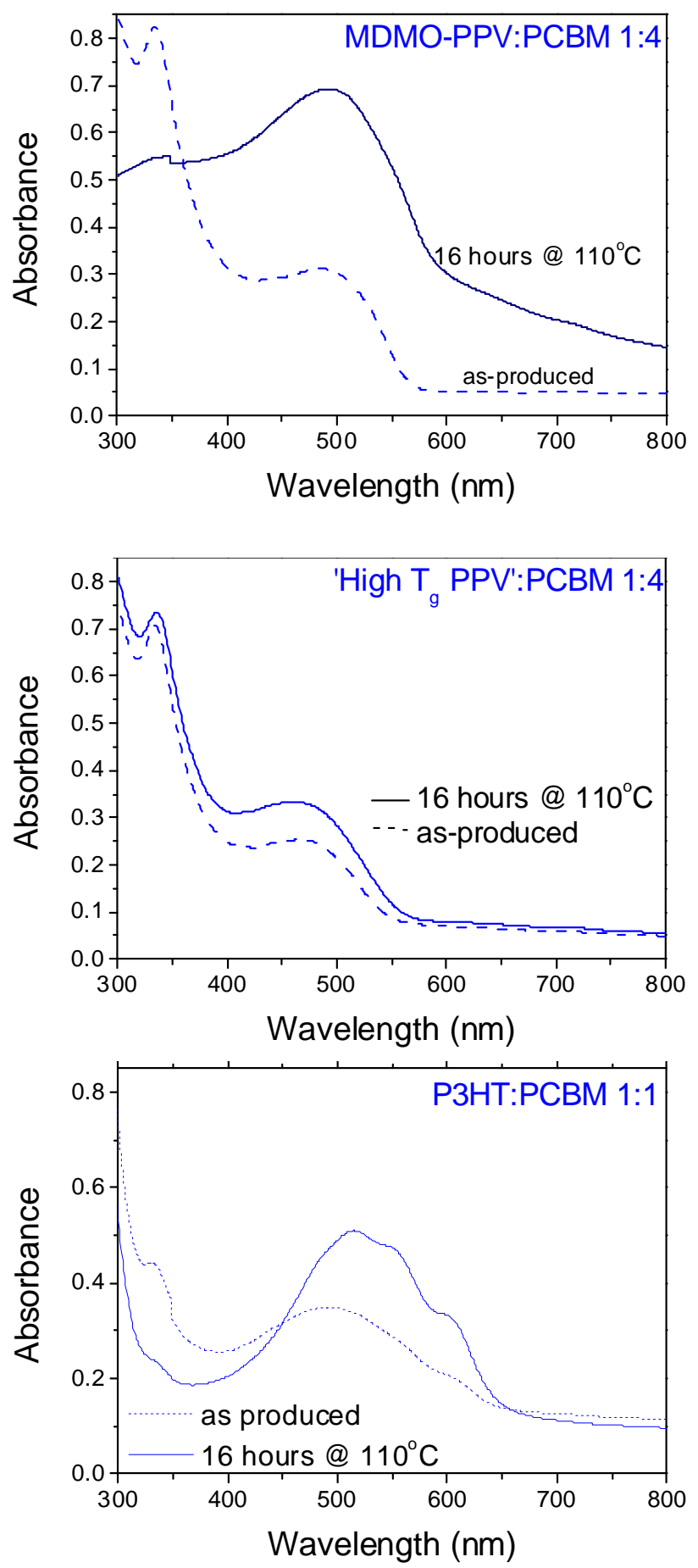

Figure 8. UV-VIS absorption spectra of MDMO-PPV:PCBM (1:4), 'High $\mathrm{T}_{\mathrm{g}}$ PPV':PCBM (1:4) and P3HT:PCBM (1:1) films. Both the spectra of the as-produced films and after a heat treatment of 16 hours at $110^{\circ} \mathrm{C}$ are shown. 


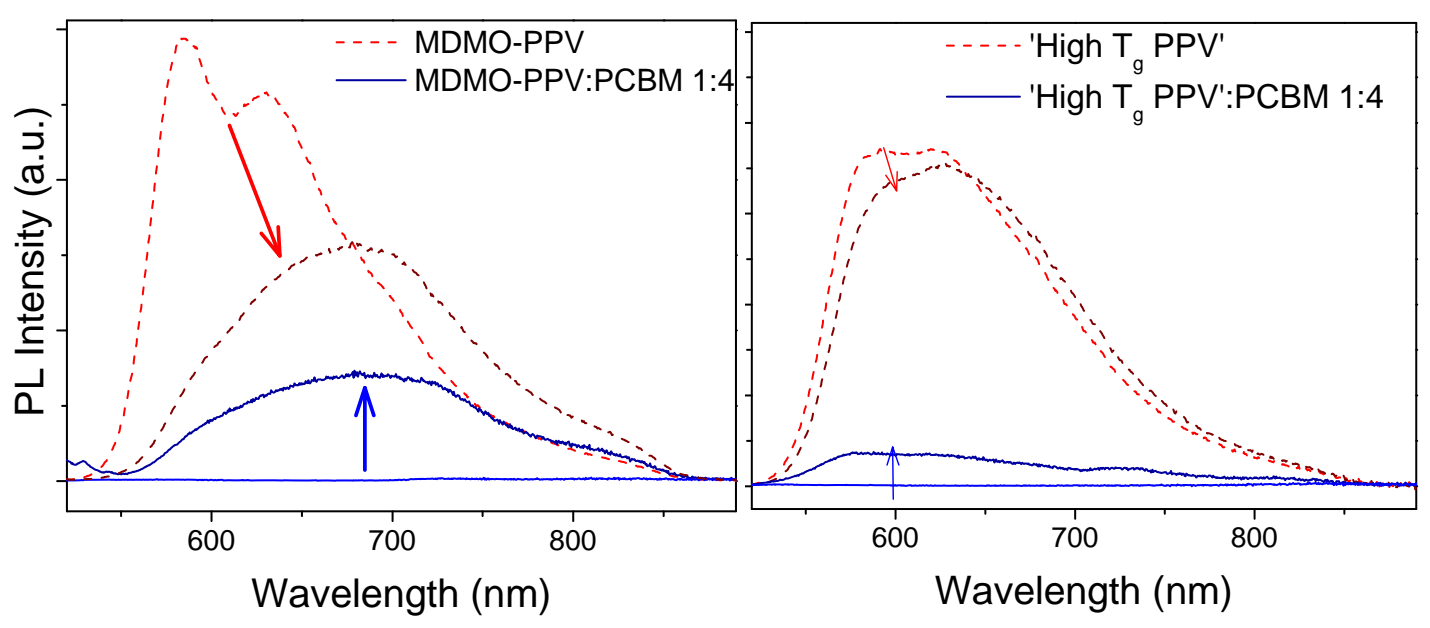

Figure 9. PL spectra from pure and blended MDMO-PPV and 'High $\mathrm{T}_{\mathrm{g}} \mathrm{PPV}$ ' (1:4 ratio). The arrows indicate the effect of thermal heating during 16 hours at $110^{\circ} \mathrm{C}$. Note that the major effect in the pure MDMO-PPV film occurs within 3 minutes. 